\title{
DNA-technologies in rice breeding for resistance to bio- and abiotic stressors
}

\author{
Dubina E.V.*, Ruban M.G., Garkusha S.V., Lesnyak S.A. \\ Federal Scientific Rice Centre, Krasnodar, Belozerny, Russia \\ *email: lenakrug1@ rambler.ru
}

According to the degree of harmfulness for rice, blast (the causative agent - fungus Pyricularia oryzae Cav.) takes the first place. Weeds compete with crops for light, mineral nutrition and space. In the system of plant protection against diseases, the most effective and environmentally friendly method is development of "immune" rice varieties with genes for resistance to blast infection $\mathrm{Pi}$, and in the fight against weeds varieties with genes for tolerance to prolonged immersion of plants under water (Sub1), as a factor of controlling weeds, and their rapid introduction into production.

Based on the use of modern technologies of molecular DNA marking, we introduced and pyramided the genes for blast resistance Pi-ta, Pi-b, Pi-1, Pi-2, Pi-33 and tolerance to prolonged flooding Sub1 A in domestic rice varieties to give them long-term resistance and tolerance to these stressors.

As a result of a number of backcrosses, breeding material with introduced and pyramided genes for blast resistance and tolerance to prolonged flooding was obtained. The control of dominant alleles of target genes during the breeding process was carried out using molecular labeling methods.

The phytopathological evaluation of the obtained lines showed their resistance to M. grisea. Rice varieties Allians, Lenaris with the Pi-ta gene were released in 2019 and 2020 respectively, rice varieties Utes with the Pi-2 gene and Voskhod (Pi-2, Pi-33), adapted to growing conditions in the south of Russia, resistant to the Krasnodar population of the pathogen, as well as having high yield and quality, were submitted for State variety testing in 2020. Phenological assessment of resistance to prolonged submergence of rice breeding samples with a complex of Pi and Sub1A genes made it possible to select forms that are tolerant to this stressor.

The introduction and cultivation of such varieties in production will make it possible to reduce the use of chemical means of protection, to obtain environmentally friendly agricultural products and to avoid pollution of grain ecosystems. 